\title{
A Novel Biologically Active Mixture (Bam) with Anti-Tumoral and Anti-Atherosclerotic Effects: Report of In Vitro Efficacy
}

\author{
Hakan Bozcuk*, Durmuş Burgucu and Metin Barut \\ Department of Medical Oncology, Medical Park Hospital, Turkey
}

Submission: November 30, 2017; Published: January 25, 2018

*Corresponding author: HakanBozcuk, Department of Medical Oncology, Medical Park Hospital, Turkey, Tel: 0090505 6728038; Fax: 0090242 3143030; Email: hbozcuk@gmail.com

\begin{abstract}
Purpose: The role of food nutrients in the protection and slowing of chronic disease states like cancer and atherosclerosis is not clearly defined; proper nutrition is believed to play a larger role in the protection of atherosclerosis than that of cancer. We aimed to test the effect of a Biologically Active Mixture (BAM) that includes specifically selected active nutrients on the process of atherosclerosis and on cancer cells.

Material and Methods: After a comprehensive literature search, 8 super food items were selected. We utilized MTT tests in vitro to determine the effect of the combination of these super food items, BAM, on atherosclerosis and cancer cells. The amount of each super food item in BAM was calculated on the basis of data from literature if direct human data existed, and by extrapolation from animal studies at the absence of human data. BAM contained 2 types of fruits, 2 types of spices, 2 kinds of grains and 2 types of plant tea. To test the in vitro cytotoxic effects of BAM, smooth muscle cell culture isolated from rat arteries, HEK293 kidney cells, and A549 lung cancer cell lines were used.
\end{abstract}

Results: BAM exerted direct cytotoxicity in all 3 cell lines. The per cent cell inhibition rates by BAM were as follows: 65\% in rat artery smooth muscle cell culture, 74\% in HEK293 kidney cell line, and 71\% in A549 lung cancer cell line.

Conclusion: This preliminary data suggests BAM has anti- atherosclerotic and anti- cancer effects.Thus, BAM may have potential complementary preventive and therapeutic effects for a number of chronic disease states. Given the huge burden of chronic disease states on health outcomes, further clinical studies are needed to comment further on the therapeutic and preventive effects of BAM, as well as the mechanism of these effects.

Keywords: Cancer; Atherosclerosis; Cytotoxicity; Super food

\section{Introduction}

It is well known that chronic inflammation is an age related process ("inflamm-aging") and linked with metabolic, cardiovascular, neurological diseases as well as cancer, osteoporosis and frailty [1-8]. In addition, diet is also known to be associated with inflammation where a diethigh in refined starches, trans-fats and low in omega- 3 fatty acids, fibers and whole grains is known to promote inflammation [9]. Likewise, participants of Nurses' Health Study who consumed a more 'westernized' diet had higher CRP and IL-6 levels [10]. Interestingly, diet is also a source of some active compounds, like Apigenin, a flavonoid, which suppresses inflammation, retards cell proliferation, and may be preventive against chronic inflammatory states including cancer [11]. In parallelism, there are some natural "super food" items containing active ingredients that have been shown to inhibit both cancerogenesis and atherogenesis in laboratory and animal models with or without data from clinical studies. Inflammation and immunity are multifaceted phenomena and inflammation, especially in its acute form, also serves important functions to restore health [12]. Thus, in order to develop a natural form of potential anti-inflammatory mixture derived from natural nutrients, with a desirable inhibitory activity against cancer cells and atherosclerosis, we aimed to test in vitro the effect of a Biologically Active Mixture (BAM).

\section{Materials and Methods}

\section{Selection of super food items and construction of BAM}

We searched the literature for food items with reported results showing efficacy both in cancer and atherosclerosis models, and also possessing anti-inflammatory compounds, with data derived from either cell culture experiments and/or animal 
models. Literature search yielded 8 super food items, which were then used to construct BAM. The 8 super food components of BAM contained 2 types of fruits, 2 types of spices, 2 kinds of grains and 2 types of plant tea. In order to decide on the amount of each of the 8 components in the final BAM preparation, we used direct data from literature, if data from human studies existed. On the other hand, at the absence of human data, where only animal studies existed, the amount of each component in the BAM preparation was calculated by extrapolation from weight ratio of the daily consumed dose of the component over average total weight of the animal in that experiment, assuming an average human weight of $70 \mathrm{~kg}$.

\section{Preparation of BAM}

Components of BAM were used either in the form of dry powder, dehydrated fruit, freshly squeezed fruit juice or plant tea. See Table 1 for the description and amount of components used in BAM.

Table 1: Components and their amount in the daily of BAM (250 cc mixture/day).

\begin{tabular}{|c|c|c|c|}
\hline Component & Type & Form & Amount \\
\hline 1 & Spice & Dry Powder & 3 grams \\
\hline 2 & Fruit & Dried fruit & 26 grams \\
\hline 3 & Fruit & Fruit juice & $200 \mathrm{cc}$ \\
\hline 4 & Plant tea & Tea & 1 gram(in $25 \mathrm{cc}$ tea) \\
\hline 5 & Spice & Dry Powder & 0.5 gram \\
\hline 6 & Plant tea & Tea & 1 gram(in $25 \mathrm{cc}$ tea) \\
\hline 7 & Grain & Dry Powder & 20 grams \\
\hline 8 & Grain & Dry Powder & 10 grams \\
\hline
\end{tabular}

During the preparation phase, firstly component 2 was minced in a dedicated machine, and then mixed with components $1,3,5$,

Results and Discussion
7 and 8. Components 4 and 6 are first brewed, and then waited until their heat drops down to room temperature and after this stage they are added to other components. The resultant mixture is then homogenized with the help of a standard mixer and a blender. At the final stage, BAM is vacuumed, Vitamin Cadded and stored in a glass container containing the total dosage of 7 days. Potential daily dosage of BAM was set at $250 \mathrm{cc}$ in volume.

\section{Testing in vitro cytotoxicity}

To test the in vitro cytotoxic effects of BAM, 3 cell lines were used. Smooth muscle cell culture isolated from rat arteries was used to test the effect ofBAM on the atherosclerotic process. HEK293 kidney cells, and A549 lung cancer cell lines were utilized to test cytotoxicity on cancer cells, and primitive, embryonic cells. We used MTT (3-(4,5-dimethylthiazol-2-yl)2,5-diphenyl tetrasodium bromide) assays to explore growth inhibition in cell lines. MTT testing was conducted as used in the literature previously $[13,14]$.

Briefly, cancer cells were seeded into 96-well microtiter plates at appropriate densities. Cells were exposed for 72 hours to a standard concentration of BAM prepared with or without Vitamin $\mathrm{C}$, or air, and tests were repeated for a total of 3 times. After 72 hours, 20 microL of $5 \mathrm{mg} / \mathrm{ml}$ MTT was added to each well, and all plates were incubated at $37^{\circ} \mathrm{C}$ for 4 hours. Finally, DMSO (150microL) was introduced to each well and optical absorbance was read at $570 \mathrm{~nm}$. Cytotoxicity was formulated as the following: $100 \times$ (1-((absorbance of treated cells)/ (absorbance of control cells))).

\section{Statistical methods}

Percent inhibition rate by BAM in cell lines was expressed as the mean inhibition value of 3 repeated tests as compared to control (no BAM).

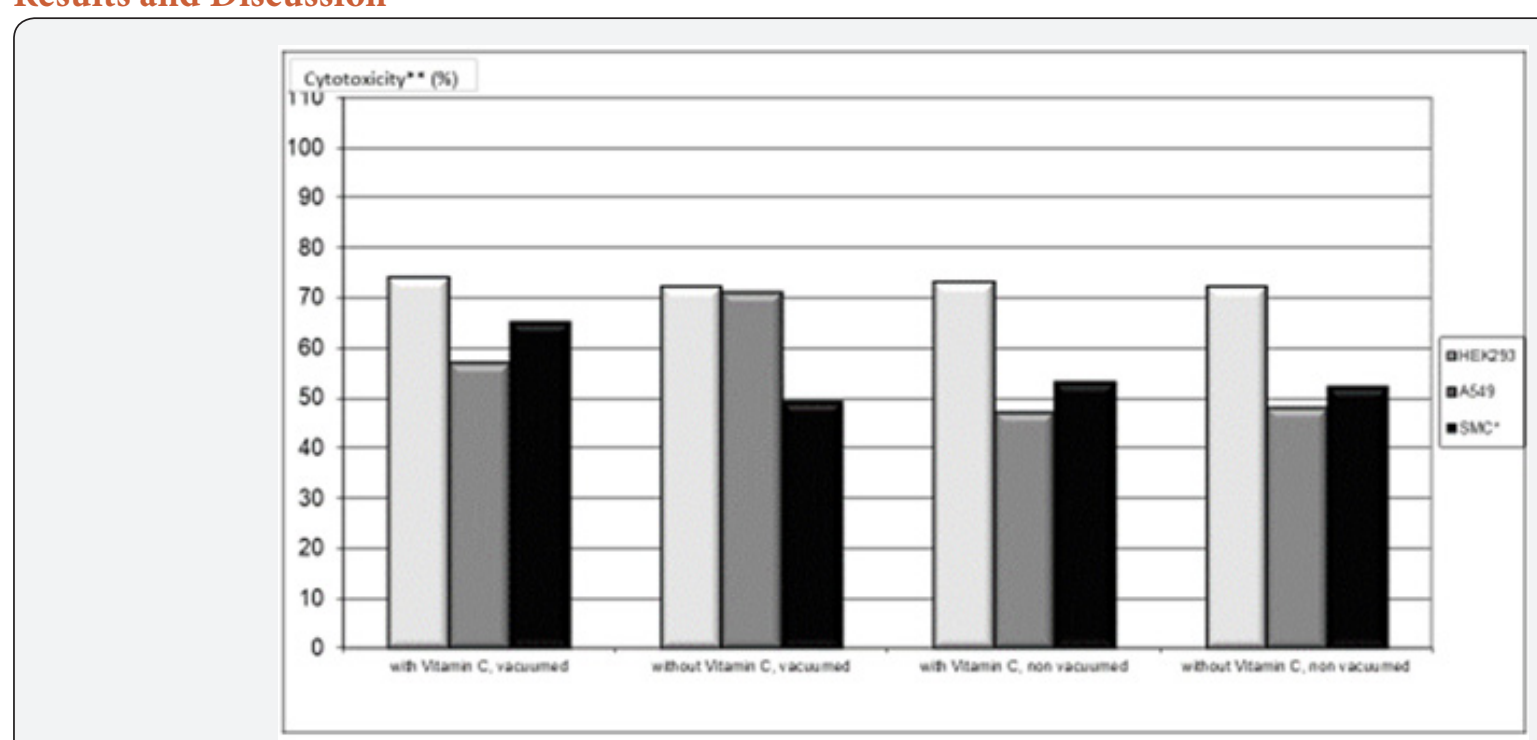

*: Rat smooth muscle cells. "*; Cytotoxicity is defined as "100 $\times$ (1-((absorbance of treated cells) $)($ absorbance of control cells $)))$ "

Figure 1: In vitro cytotoxicity of biologically active mixture (BAM). 
The inhibition rates by BAM,compared to control (no BAM), in the cell cultures utilized were as follows: $65 \%$ in rat artery smooth muscle cell culture, 74\% in HEK293 kidney cell line, and $71 \%$ in A549 lung cancer cell line. Addition of Vitamin C or vacuuming did not seem to have major impact on the cytotoxicity profile. Please refer to Figure 1 for details. Additionally, after 1 month of storage, BAM did not appear to loose cytotoxic potential as compared to no storage (freshly prepared BAM), data not shown here.

We demonstrated in this study that BAM clearly exerted cytotoxicity in all cell lines tested. Our data clearly shows the potential of BAM to inhibit at least the smooth muscle cell proliferation state in atherosclerosis, as well as cellular proliferation in cancer cells. This dual effect makes this natural mixture of 8 super food items a candidate of complementary treatment for prevention and prophylaxis of cancer and atherosclerosis. There is an also hypothetical prospective that BAM may be helpful in the treatment of these states as a complementary modality. Because components of BAM were selected and dosed on their published effects on cancer and atherosclerosis models and cell cultures, the resultant mixture, BAM, may be more effective as a sum than individual components.

Previous reports show that cancerogenesis and atherogenesis share common pathways, inflammation being one of them and some common molecules likeAlarmins, macrophage derived Wnt5a and inflammasomes take part in the pathogenesis of both of these disease states [15-17]. A possible anti-inflammatory effect of BAM additionally opens doors to the probability of prevention and treatment of other chronic inflammatory conditions such as Diabetes Mellitus, metabolic syndrome, neurological diseases, and osteoporosis. Although the anti-inflammatory effect of BAM as a mixture was not quantified in this study, it is likely, as the constituents of BAM have been separately shown to possess anti-tumoral, anti-atherosclerotic and anti-inflammatory effects.

Our findings are encouraging to advise chronic use of a natural mixture, such as BAM, which is non-toxic and may well be used as a complementary treatment modality. One of the components of BAM; component 6 , is also known to contain the ingredient Catechin which facilitates lipolysis [18-20]. Thus, BAM may also potentially be used to prevent or impede obesity, and usage during childhood and adolescence also makes sense, as weight control earlier in life has been shown to augment protection against cancer.

In short, in this study we propose a natural and non-toxic food supplement that has anti-cancer and anti-atherosclerotic effects. Our in vitro findings necessitate prospective clinical trials, to test the proposed effects alone or when used in conjunction with standard treatment methods.

\section{Conclusion}

We show in this study that a natural food supplement exerts anti-tumoral and anti-atherosclerotic effects in vitro. This finding has implications for use of this supplement (BAM) as a complementary treatment modality.

\section{Conflict of Interest}
a. No financial support was received for this study.
b. Patent pending for BAM.

\section{References}

1. Fougere B, Boulenger E, Nourhashemi B, Guyonnet S, Cesari M (2017) Chronic inflammation: accelerator of biological aging. J Gerantol A Biol Sci Med Sci 72(9): 1218-1225.

2. Caruso C, Balistreri CR, Crivello A, Irma Forte G, Grimaldi MP, et al. (2007) The genetics of innate immunity and inflammation in ageing, age related diseases and longevity. Immunosenescence, New York, USA, pp. 154-173.

3. Libby P, Ridker PM, Hansson GK (2009) Inflammation in atherosclerosis: from pathophysiology to practice. J Am Coll Cardiol 54(23): 2129-2138.

4. Koyama A, O' Brien J, Weuve J, Blacker D, Metti AL, et al. (2013) The role of peripheral inflammatory markers in dementia and Alzheimer's disease: a metaanalysis. J Gerontol A Biol Sci Med Sci 68(4): 433-440.

5. Coussens LM, Werb Z (2002) Inflammation and cancer. Nature 420(6917): 860-867.

6. Shacter E, Weitzman SA (2002) Chronic inflammation and cancer. Oncol Williston Park N 16(2): 217-226.

7. Manolagas SC (2000) Birth and death of bone cells. Basic regulatory mechanisms and implications for the pathogenesis and treatment of osteoporosis. Endocr Rev 21(2): 115-137.

8. Wu IC, Shiesh SC, Kuo PH, Lin XZ (2009) High oxidative stress is correlated with frailty in elderly Chinese. J Am GeriatrSoc 57: 16661671.

9. Giugliano D, Ceriello A, Esposito K (2006) The effects of diet on inflammation: the emphesis on the metabolic syndrome. J Am Col Cardiol 48(4): 677-685.

10. Lopez Garcia E, Schulze MB, Fung TT, Meigs JB, Rifai N, et al. Major dietary patterns are related to plasma concentrations of markers of inflammation and endothelial dysfunction. Am J ClinNutr 80(4): 10291035.

11. Sung B, Chung HY, Kim ND (2016) Role of Apigenin in cancer prevention via the induction of apoptosis and autophagy. J Cancer Prev 21(4): 216226.

12. Licastro F, Candore G, Lio D, Porcellini E, Romano CG, et al. (2005) Innate immunity and inflammation in aging: a key for undertanding age related diseases. Immun Ageing 2: 8.

13. Cui YY, Xie H, Qi KB (2005) Effects of Pinus massonia bark extract on cell proliferation and apoptosis of human hepatoma BEL-7402 cells. World J Gastroenterol 11(34): 5277-5282.

14. Kim J, Lee SK, Hwang ES (1997) Limited cytotoxic effect of ednoviral mediated p53 gene transfer in variable nsclc cell lines. J Korean Cancer 29: $565-575$.

15. Boteanu RM, Suica VI, Uyy E, Ivan L, Dimo SO, et al. (2016) Allarmins in chronic noncommunicable diseases: Atherosclerosis, diabetes and cancer. J Proteomics 153: 21-29. 
16. Shao Y, Zheng Q Wang W, Xin N, Song X, et al. (2016) Biological functions of macrophage-derived Wnt5a, and its roles in human diseases. Oncotarget 7(41): 67674-67684.

17. Rimessi A, Previati M, Nigro F, Wieckowski MR, Pinton P (2016) Mitochondrial reactive oxygen species and inflammation. Molecular mechanisms, diseases and promising therapies. Int J Biochem Cell Biol 81(Pt B): 281-293.

18. Shirakami Y, Sakai H, Kochi T, Seishima M, Shimizu M (2016) Catechins and its role in chronic diseases. Adv Exp Med Biol 929: 67-90.
19. Suzuki T, Pervin M, Goto S, Isemura M, Nakamura Y (2016) Beneficial effects of tea and the green tea catechin Epigallocatechin-3-gallate on obesity. Molecules 21(10): E1305.

20. Ferreira MA, Silva DM, deMorais Ac, Mota JF, Betelho PB, et al. (2016) Therapeutic potential of green tea on risk factors for type 2 diabetes in obese adults-a review. Obes Rev 17(12): 1316-1328.

\section{Your next submission with Juniper Publishers will reach you the below assets}

- Quality Editorial service

- Swift Peer Review

- Reprints availability

- E-prints Service

- Manuscript Podcast for convenient understanding

- Global attainment for your research

- Manuscript accessibility in different formats ( Pdf, E-pub, Full Text, Audio)

- Unceasing customer service

Track the below URL for one-step submission https://juniperpublishers.com/online-submission.php 